\title{
Emerging Applications of Blockchain Technology on a Virtual Platform for English Teaching and Learning
}

\author{
Ping Wang $\mathbb{D}^{1}$ and Shuhan Qiao $\mathbb{D}^{2}$ \\ ${ }^{1}$ School of Foreign languages, Jiujiang University, Jiujiang 332005, China \\ ${ }^{2}$ Shandong Provincial Research Center of Demonstration Engineering Technology for Urban and Rural Landscape, \\ Taian 271000, China \\ Correspondence should be addressed to Shuhan Qiao; qiaoshuhan@sdau.edu.cn
}

Received 16 October 2020; Revised 5 November 2020; Accepted 27 November 2020; Published 8 December 2020

Academic Editor: Hongju Cheng

Copyright ( 92020 Ping Wang and Shuhan Qiao. This is an open access article distributed under the Creative Commons Attribution License, which permits unrestricted use, distribution, and reproduction in any medium, provided the original work is properly cited.

\begin{abstract}
To extend a broad application of blockchain technology to the fields of online English education, this paper aims to improve a virtual platform for English teaching and learning of landscape design majors, mainly composed of presentation layer, business layer, and data layer by analyzing the performance of the proposed algorithm, and comparing with other existing algorithms. In the platform, through the service layer, the communication between the presentation layer and the data layer is completed, and the data in the data layer is transferred to the presentation layer. The user first establishes a connection with the server in the presentation layer. Using the transmitted data information, the server assigns an identifier to the user and establishes a role model. Users can download the teaching courseware through the server and simulate the real learning scene by controlling the interaction of XAML files. The results show that the virtual teaching platform makes the interconnection of users (students and teachers), machines, and things at any time and any place; realizes information self-verification, transmission, deep unsupervised learning, and management; and gives students a more realistic visual experience in high security.
\end{abstract}

\section{Introduction}

Blockchain is a term in the field of information technology. In essence, it is a Shared database of data or information that is "not falsifiable," "traces," "open and transparent," and "collective maintenance". Based on these characteristics, blockchain technology has laid a solid foundation of "trust," created a reliable "cooperation" mechanism, and has a broad application prospect. In recent years, blockchain technology is closely related to people's production and life in public management, energy, transportation, and other fields. Its technology does not rely on additional third-party management institutions or hardware facilities, and there is no central control. In addition to the self-contained blockchain technology itself, each node realizes information self-verification, transmission, and management through distributed accounting and storage. Decentralization is the most prominent and essential feature of blockchain technology [1].
However, although online teaching and learning has already been used widely in China, especially in the coronavirus epidemic, a series of old virtual platforms have not adapted to the change and development. The centralization of this field also brings some problems, which can be transformed by blockchain technology.

According to the survey, the concerns of web-based distance education are mainly focused on resources, quality, management, and teaching interaction. These are the main concerns of students and the main factors that restrict the quality of online education. With the continuous development of the second generation of website technology, a number of new network platforms for education have greatly improved the quality and efficiency of modern education and deepened the experience of teacher-student interaction in the network environment [2]. It is also in line with the requirements of modern education. With the rapid development of modern Internet technology, many universities at 
home and abroad are actively researching and developing Internet-based online education platforms to build more effective virtual campuses.

In addition, influenced by the traditional teaching mode, the English classroom teaching for landscape design majors completes the unit's teaching tasks according to the unit structure of the textbook [3]. The teaching process focuses on language learning and lacks the introduction of English culture; it highlights the monopolistic role of teachers but ignores the subjective status of students and the communicative activities that students need.

At present, web-based distance education based on blockchain for Internet of Things will become an important way, both in terms of the development of the school itself and the needs of society. Based on the research contents of the above scholars, this paper makes a contribution in the following ways:

(1) This paper reviews the existing educational information platforms based on blockchain technology for Internet of things and analyzes their advantages and disadvantages

(2) An improved virtual English teaching platform for landscape design majors is proposed, which combines deep unsupervised learning, machine learning, and self-contained blockchain technology itself

(3) The performance of the proposed algorithm is analyzed and compared with other existing algorithms, and its advantages are used to improve the virtual teaching platform of landscape design majors

This paper is organized as follows. Section 2 shows the related work. Section 3 describes the related materials and methods. And result analysis is given in Section 4, including electronic whiteboard, design of virtual scenes, energy consumption, the number of simultaneous online users, and teaching effects. Section 5 discusses the improved English virtual teaching platform for garden design majors which is based on virtual reality technology. Finally, Section 6 outlines the conclusions and puts forward a reasonable basis for practice for further reference.

\section{Related Work}

Compared with the English teaching for garden design majors in the traditional environment and the network environment, the traditional online teaching platform is based on online video as the main carrier for distance learning. The interaction between teachers and students is not strong, and its expression is relatively simple, lacking timely and effective feedback, which is not conducive to stimulating students' enthusiasm for learning, and greatly reduces the quality of teaching [4]. In the network-based English teaching for garden design majors, the learner is the main body of learning, with learning autonomy; the teacher only carries out the necessary organization, guidance, and examination for the students, which is also the application of the "constructivism" theory in teaching [5]. Constructivism emphasizes the sub- jective ability of students in learning and believes that students are the subject of learning. Knowledge is not obtained through the teacher's teaching, but the learner obtains it through the meaning construction in the certain social background, with the help of others and the necessary learning resources. Constructivism requires students to be transformed from passive recipients of internal stimuli and indoctrination of knowledge into active participants, discoverers and processors of information, and active constructors of meaning. Teachers are required to be transformed from instructors and indicators of knowledge into instructors, facilitators, and organizer of student learning [6]. Therefore, it is very urgent to construct an online teaching platform with strong interactivity, effective feedback, and rich expression.

The teaching platform has good interactivity, but the platform teaching clarity and fluency are low. Wang Pingping created a multidimensional virtual teaching platform for English, which can fully meet the needs of schools, teachers, and students. However, when the number of online users on the virtual teaching platform is large, there will be a stutter phenomenon. After the above analysis, the English virtual teaching platform for garden design majors is constructed. Combined with the advantages of the above scholars' research, the original virtual teaching platform for English teaching is improved to improve the performance of the English virtual teaching platform for garden design majors.

\section{Materials and Methods}

3.1. Improved Design of Virtual Teaching Platform. The improved English virtual teaching platform for garden design majors designed in this paper is the three-layer B/S mode. The development technology mainly uses XAML,. NET, and Javascript. The database uses SQLServer 2005 [7]. The framework of the improved English virtual teaching platform for garden design majors is shown in Figure 1.

It can be seen from Figure 1 that the virtual teaching platform for landscape design English based on machine learning algorithm includes the presentation layer, business layer, and logic layer. The presentation layer realizes the user interaction with the whole platform by inserting the browser plugin Silverlight into the web browser. The business layer is mainly responsible for all kinds of logical services of the platform, completing the communication between the presentation layer and the data layer. For example, virtual lab scenarios are generated by calling virtual components and learning generated by calling virtual components and learning module information in the database. The data layer provides data information required by the platform, such as scene information and role information [8].

After logging in, the user establishes a connection with the server, and the server assigns an identity to it. The character model was created, and the English teaching courseware for garden design majors was downloaded. Through the XAML control file, interactions are performed and real learning scenarios are simulated. At the same time, the server is also responsible for storing the shared space, managing and maintaining the consistency of the virtual teaching scene, and listening to the client's connection request and response 


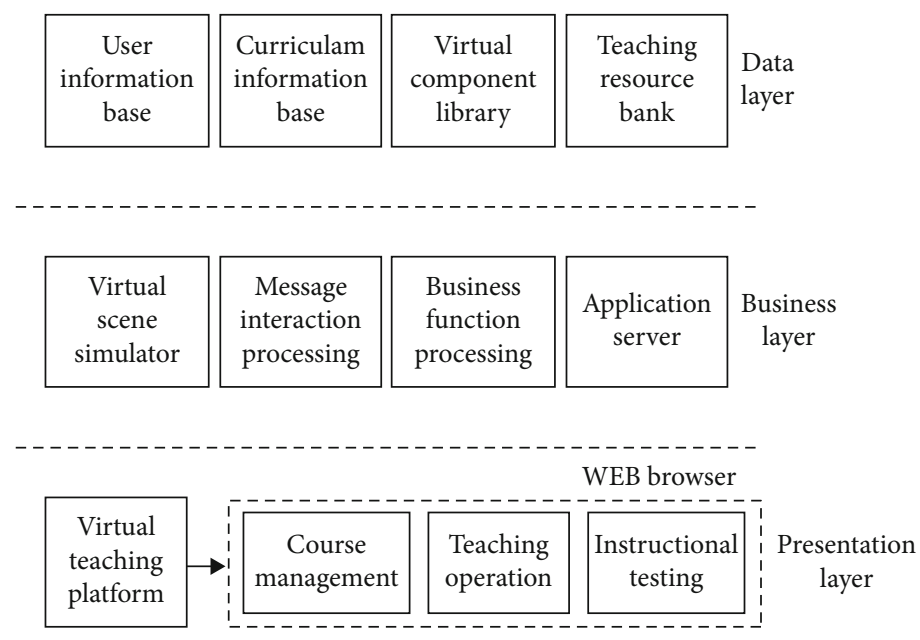

FIGURE 1: Schematic diagram of virtual teaching platform framework.

connections. The client is browser based. The first time you use it, it takes less than a few seconds to automatically download and install the browser plugin Silverlight. The client program runs in the browser as a plug-in, creates a socket connection with the server, and receives the server's message for parsing [9]. The request of the client is sent to implement the update of the virtual scene and the user interaction. The information interaction in the English virtual teaching platform for garden design majors is more important. Through information interaction, users can create an immersive feeling to enhance user interest and promote user learning [10]. The information interaction model designed in this paper is shown in Figure 2.

As can be seen from Figure 2, through the information interaction model, the platform can provide users with a more realistic and virtual English teaching environment for garden design majors, while users can perceive the most realistic teaching effects from the aspects of vision, hearing, and virtual environment.

3.2. Platform Features. The improved English virtual teaching platform for garden design majors consists of two parts: the front desk and background of the virtual teaching platform. The improved front desk of English virtual teaching platform for garden design majors mainly includes the student platform, teacher platform, user login, and user registration function modules. The improved background of the English virtual teaching platform for garden design majors mainly completes the user management, platform maintenance, teacher review, course review, and release notification of the virtual teaching platform [11].

3.2.1. Front Desk Function. The improved front desk of the English virtual teaching platform for garden design majors is mainly composed of the teacher function module and the student function module [12]. The front desk mainly includes the student platform, the teacher platform, and the registration and login function. The student platform module provides online learning for students, including onsite mail, the latest course presentations, the latest resource presentations, student classes, and personal information maintenance. Among them, the student classroom is the key function of the student platform, which includes online video, online discussion groups, online courseware browsing, and other functions.

It provides a good learning platform for students. The teacher platform module mainly includes the release of the experimental course, the release of the teaching course, and the maintenance of the teaching course. Among them, the teaching course publishing function is the key function module of the teacher platform, which includes functions such as applying for the course, adding the discussion group, releasing the teaching courseware, and releasing the video. It provides a variety of resources for students to learn online [13].

(1) Electronic Whiteboard. The e-learning whiteboard allows multiple people to simultaneously draw graphics on the whiteboard and send text messages, all of which will be reflected on each user's screen. Therefore, through the electronic whiteboard, teachers and students and students and students can have convenient communication and discussion. The electronic whiteboard is implemented by XAML + WCF. XAML is used as a presentation layer for drawing whiteboards, and feedback from user operations is passed through WCF. The core purpose of WCF is to allow programs to communicate with other programs on the same computer or network, or across the Internet [14].

(2) Student Function Logic. Students must meet two conditions to enter the student platform: first, the user must have completed registration. Student users must be registered with the platform before they can log in to the platform. The platform verifies the user's necessary registration information when the student user logs in to the platform. If the platform detects that the user has not completed the necessary information, it will return to the user details registration page so that the user can continue to complete the registration. The second condition is that the user must pass the platform authentication. Student business logic is shown in Figure 3. 


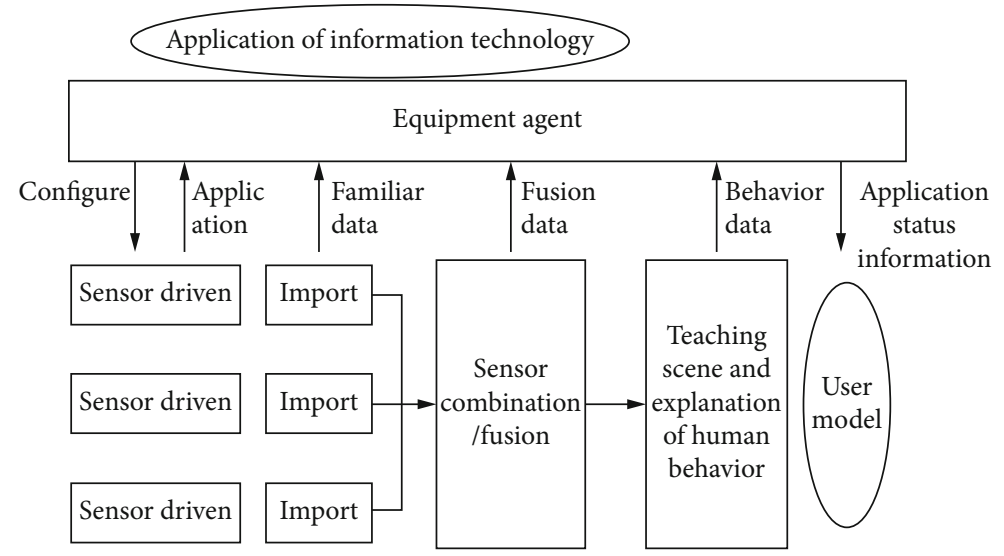

FIgURE 2: Platform information interaction model.
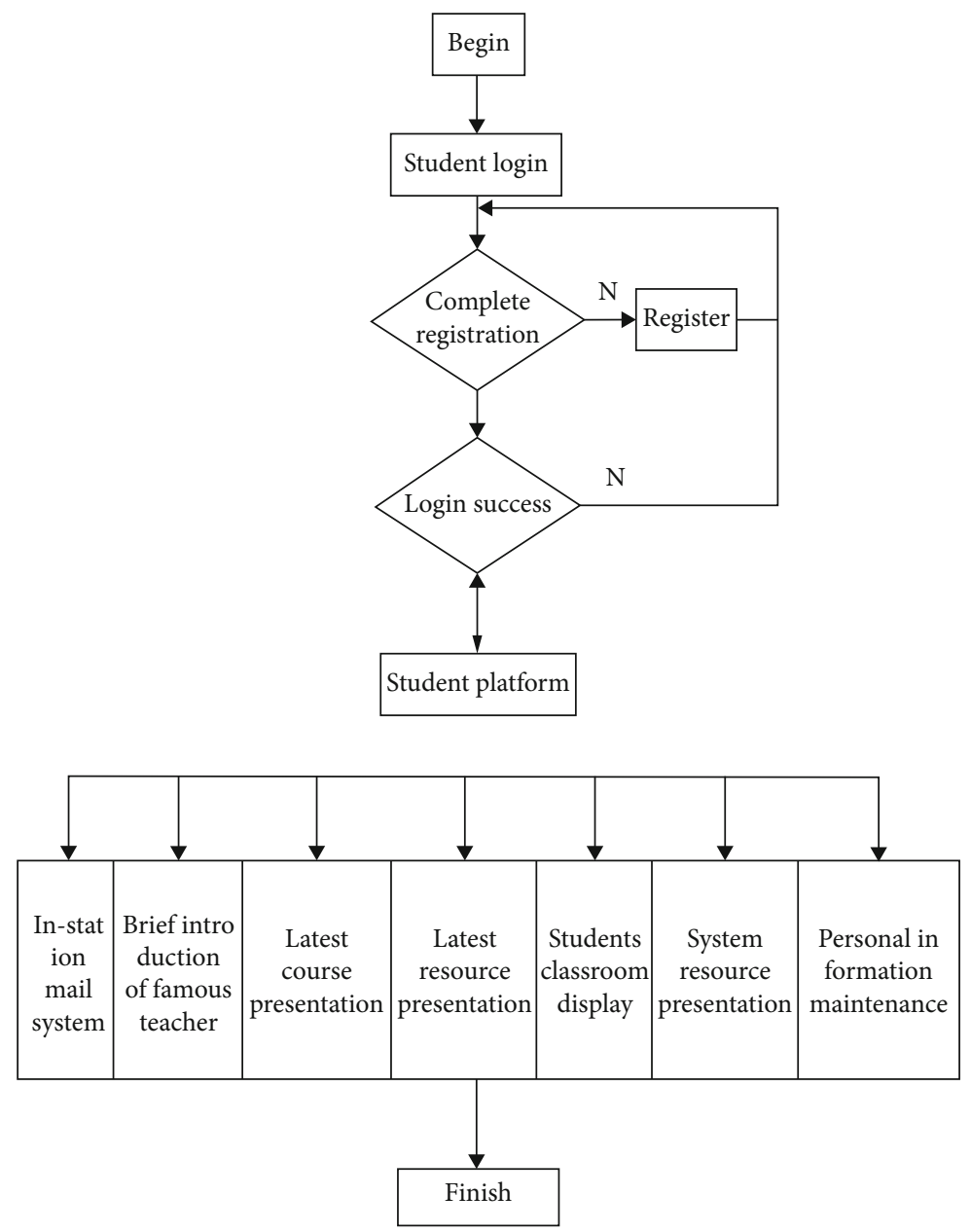

FIgURE 3: Student functional logic.

It is known from the student function logic that students can only use the platform after they have been authenticated. The specific functions that the student platform provides to students are as follows: the in-site mail platform (including the functions of mail sending, mail receiving, and announcement display and address book). The mail sending function can be used for mail communication between platform users, and users can view the sent mail records in their own outbox [15]. The mail receiving function allows the user to receive mail, and the user can view the received mail in the inbox. The announcement display feature displays the latest announcements from the administrator. Contacts can help users find contacts quickly when they need to send in-site mail. The Master Profile feature provides a teacher avatar 
scrolling feature on the student home page. Students can always check the latest course information of the teachers they are interested in. By reviewing the latest approved course information, students can easily learn the latest courses to learn about the courses they are interested in [16]. The latest resource information display feature makes it easy for students to learn about the latest uploaded courseware, video tutorials, and other available teaching resources. Student Classroom Display: this feature is a key feature of the virtual course platform, which provides a good online learning platform for student users.

3.2.2. Background Function. The background of the improved English virtual teaching platform for garden design majors has the following functions: platform maintenance, personnel management, classroom information setting, and course information management [17]. The platform background is mainly to support the management and maintenance of the web-based virtual teaching platform. The platform background includes platform information maintenance, course review, teacher review, release notification, personnel management, subject and professional management, and administrator password modification. Among them, platform information maintenance refers to the initialization of the virtual teaching platform, the recovery of the database dictionary, the setting of the number of people in the online classroom, and the backup and restoration of the database [18]. Personnel management includes information management for users such as students and teachers, as well as management of administrators. The background of the improved English virtual teaching platform for garden design majors has only one type of administrator [19]. The following functional logic for the administrator is designed as follows. First, administrators also need to authenticate when they enter the platform. When the administrator logs in to the platform, the platform will verify the login information of the user. After the verification is passed, the platform automatically records the administrator's user name, number, and user name, number, and user role in the session object. This is also the important document that the administrator has logged into the platform. The user function logic is shown in Figure 4.

As can be seen from Figure 4, the administrator can log in to the platform and authenticate before entering the background management platform. When the administrator enters the background management platform, the platform can be managed and maintained. Among them, the platform basic information maintenance functions include platform initialization, data dictionary recovery, and database backup and restore. Platform initialization includes initialization of platform default settings and creation of some necessary folders [20]; data dictionary recovery is to prevent the platform from running abnormally due to malicious tampering with the original data in the database; the course review function allows the administrator to review the course applied by the teacher. The course review status includes pending review, pass, and fail. Before the teacher applies for the course to the final review of the administrator, the course status is pending review, and only after the applied course has been

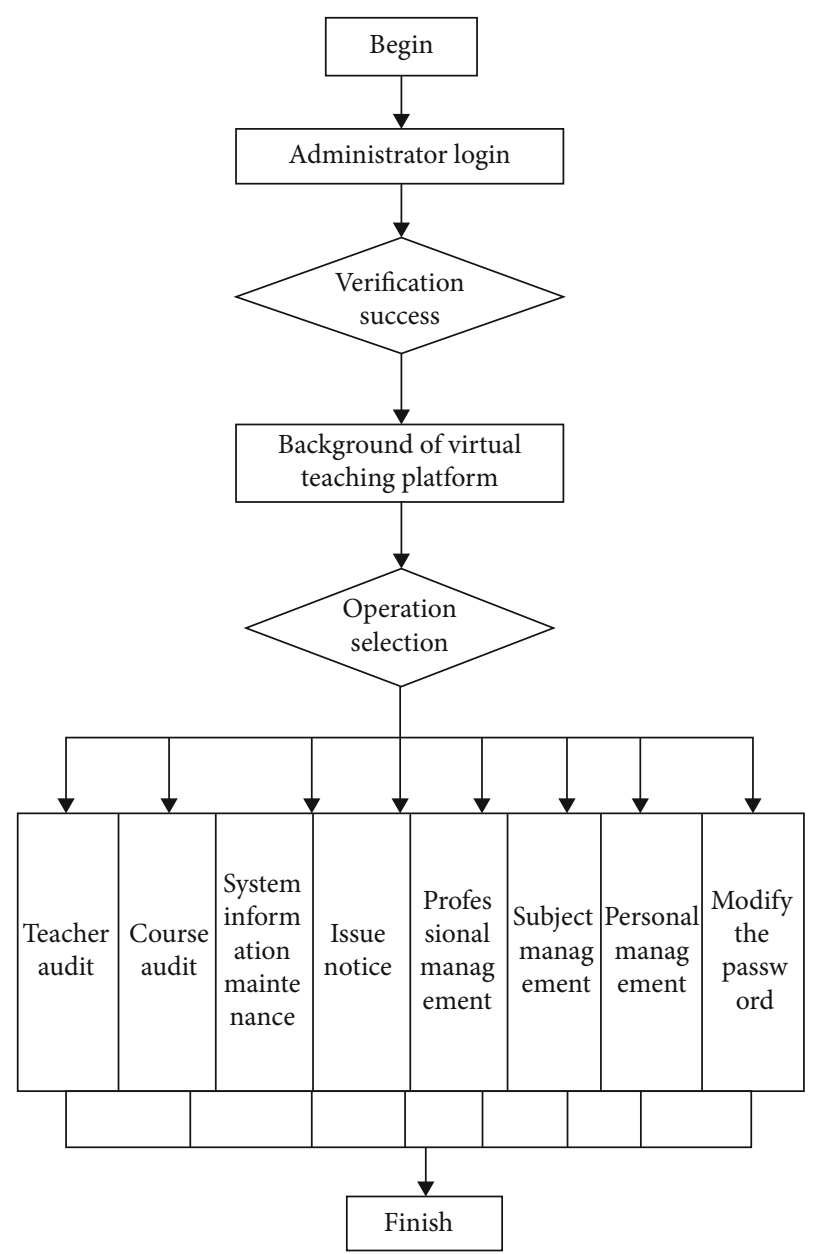

FIgURE 4: Ends with a user function logic diagram.

approved, can it open to the students. The administrator uses the teacher review function to review newly registered teachers, and only users registered as teachers need to be reviewed [21].

\section{Results}

4.1. Electronic Whiteboard. To verify the effect of the whiteboard application in the improved English platform for landscape design majors of this article, actual testing is required. The effect of the whiteboard application in the platform is shown in Figure 5.

As can be seen from Figure 5, the teacher can show the garden design majors English to the students through the whiteboard. When the teacher writes the wrong English word on the electronic whiteboard, the wrong letter on the whiteboard can be cleared by the eraser button on the whiteboard interface, and at the end of the course, the teacher can click the button to clear all the texts on the whiteboard. On the electronic whiteboard interface, there is a user communication interface. Students can send questions to the teacher through the communication interface on the electronic whiteboard, and the teacher can watch and reply through the interface. After the above analysis, it is found that the 


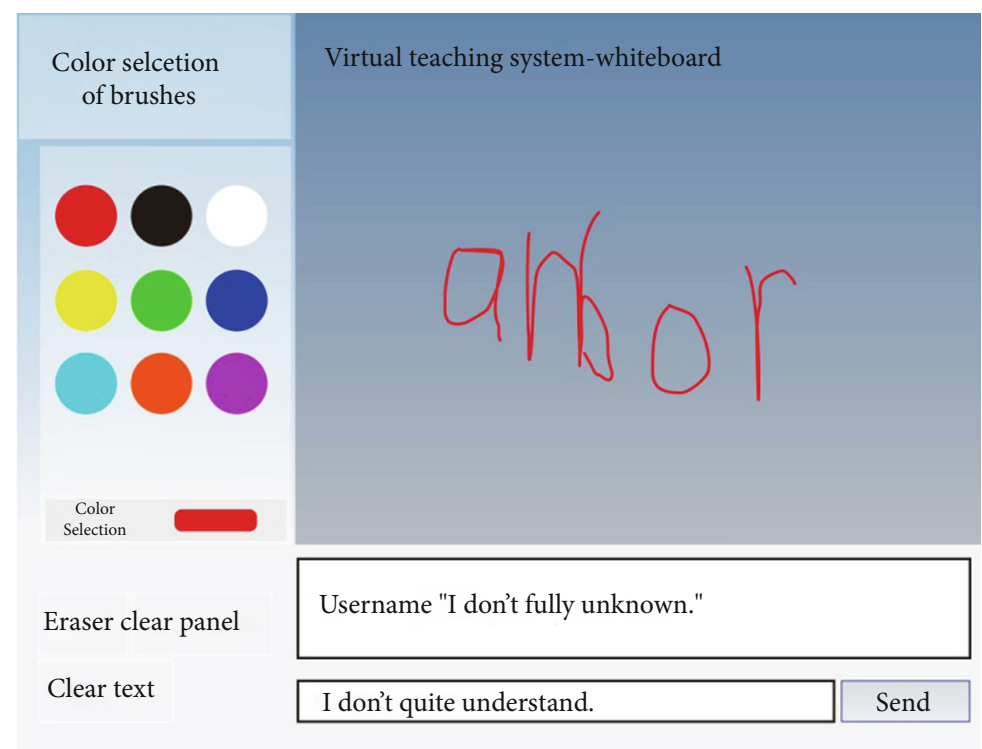

Figure 5: Electronic whiteboard display diagram.

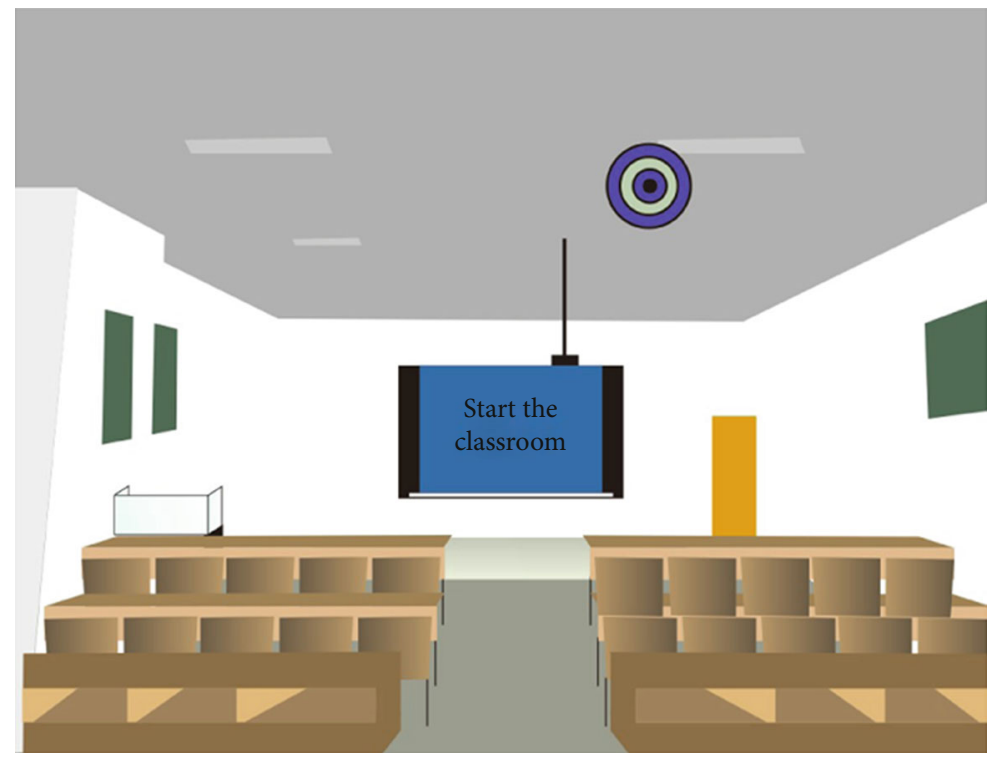

Figure 6: Virtual classroom design.

electronic whiteboard in the improved English virtual teaching platform for garden design majors has the better effect.

4.2. Design of Virtual Scenes. To verify the effect of the teaching scene in the improved English virtual teaching platform for garden design majors designed by this method, the actual analysis is needed. The virtual classroom scene obtained by using the virtual teaching platform is shown in Figure 6.

As can be seen from Figure 6, after the student logs in to the platform, he or she chooses a course of study and then enters the virtual classroom. Virtual classrooms are built in a simulated reality classroom that includes elements such as windows, fluorescent lights, desks and chairs, podiums, projectors, blackboards, and slides. After entering the virtual classroom, students can move freely in the classroom. When the mouse moves to the slide element in the virtual classroom, they will see the slogan prompting "start the classroom." After clicking the slogan, they can enter the classroom to learn. That is to say, the improved English virtual teaching platform for garden design majors has better interaction performance.

4.3. Energy Consumption. To verify the energy consumption of virtual teaching platform in this method, under different teaching time, the energy consumption of the teaching platforms designed by the method of this paper, the design method of virtual teaching platform based on cloud architecture, and the design method of the virtual teaching platform based on MVC should be compared. The comparison results are shown in Table 1. 
TABLE 1: Comparison of energy consumption results.

\begin{tabular}{|c|c|c|}
\hline Method & $\begin{array}{l}\text { Teaching } \\
\text { time/h }\end{array}$ & $\begin{array}{c}\text { Expenditure of } \\
\text { energy/J }\end{array}$ \\
\hline \multirow{11}{*}{ The method of this paper } & 0.5 & 236.458 \\
\hline & 0.6 & 239.346 \\
\hline & 0.7 & 241.527 \\
\hline & 0.8 & 243.674 \\
\hline & 0.9 & 244.532 \\
\hline & 1 & 249.671 \\
\hline & 1.1 & 250.918 \\
\hline & 1.2 & 252.634 \\
\hline & 1.3 & 255.315 \\
\hline & 1.4 & 258.619 \\
\hline & 1.5 & 260.056 \\
\hline \multirow{11}{*}{$\begin{array}{l}\text { Design method of teaching virtual } \\
\text { platform based on cloud architecture }\end{array}$} & 0.5 & 346.826 \\
\hline & 0.6 & 349.798 \\
\hline & 0.7 & 353.264 \\
\hline & 0.8 & 357.684 \\
\hline & 0.9 & 361.258 \\
\hline & 1 & 365.947 \\
\hline & 1.1 & 369.793 \\
\hline & 1.2 & 373.213 \\
\hline & 1.3 & 377.192 \\
\hline & 1.4 & 381.648 \\
\hline & 1.5 & 385.975 \\
\hline \multirow{11}{*}{$\begin{array}{l}\text { Design method of virtual teaching } \\
\text { platform based on MVC }\end{array}$} & 0.5 & 468.249 \\
\hline & 0.6 & 476.364 \\
\hline & 0.7 & 484.456 \\
\hline & 0.8 & 492.359 \\
\hline & 0.9 & 500.681 \\
\hline & 1 & 508.163 \\
\hline & 1.1 & 516.254 \\
\hline & 1.2 & 524.794 \\
\hline & 1.3 & 532.618 \\
\hline & 1.4 & 540.023 \\
\hline & 1.5 & 548.315 \\
\hline
\end{tabular}

It can be seen from Table 1 that the method consumes the least amount of energy in the same teaching time. After statistical analysis, the average energy consumption of the proposed method in various cases is $248.431 \mathrm{~J}$, while the average energy consumption of the other two methods is $365.691 \mathrm{~J}$ and $508.388 \mathrm{~J}$, respectively. That is, the English virtual teaching system for garden design majors designed by this method consumes the least amount of energy in the actual process.

4.4. Analysis of the Number of Simultaneous Online Users. Two computers with the same configuration were selected as the experimental objects, one of which was equipped with the ordinary English virtual teaching platform for gar- den design majors, and the other was equipped with the improved English virtual teaching platform for garden design majors. One thousand students from a university $\log$ in to the two platforms at the same time and learn English with the garden design majors online. Finally, the number of simultaneous online users allowed by the course of the two platforms is separately counted. The number of online students in the course is the same as the change in the SJF indicator. When the SJF indicator increases, the number of online students can increase at the same time; otherwise, it decreases. Before and after the improvement, the comparison of the number of online users is shown in Figure 7.

Figure 7(a) shows that when the upper limit of the number of online users is 500, the preimprovement English virtual teaching platform for garden design majors is applied. At $10 \mathrm{~s}$, the virtual teaching platform has a maximum of 286 online users. After the application of the improved virtual teaching platform, the virtual teaching platform can reach a maximum of 500 people online at $12 \mathrm{~s}$. Analysis of Figure 7(b) shows that when the upper limit of the number of online people is greater than 500, the preimprovement English virtual teaching platform for garden design majors is applied. At $6.8 \mathrm{~s}$, the number of simultaneous online users on the virtual teaching platform reached a maximum of 805 . After applying the improved virtual teaching platform, at $8.2 \mathrm{~s}$, the number of simultaneous online users on the virtual teaching platform reached a maximum of 968 . Therefore, it can be proved that the number of online viewers has been greatly improved after applying the improved English virtual teaching platform for garden design majors.

4.5. Analysis of Teaching Effect. To comprehensively verify the teaching effect of the virtual teaching platform designed in this paper, 10 students from a certain university are randomly selected for actual investigation. The virtual teaching platforms designed by the three methods were scored with a score of 10 , and the results are shown in Table 2 .

It can be seen from Table 2 that the overall teaching effect of the English virtual teaching platform for garden design majors improved by this method is better. The above data shows that the clarity and fluency of the teaching platform designed by this method are higher than 9 points. The teaching effects of the virtual teaching platform designed by the other two methods are lower than the method of this paper. That is to say, through comparative analysis, the actual teaching effect of the virtual teaching platform designed by this method is better.

\section{Discussion}

After theoretical analysis and experimental verification, the improved English virtual teaching platform for garden design majors is based on virtual reality technology. There is a big difference between the improved English virtual teaching platform for garden design majors and the traditional English virtual teaching platform for garden design majors. It mainly immerses people in a variety of senses and interacts with this realistic environment. The improved 


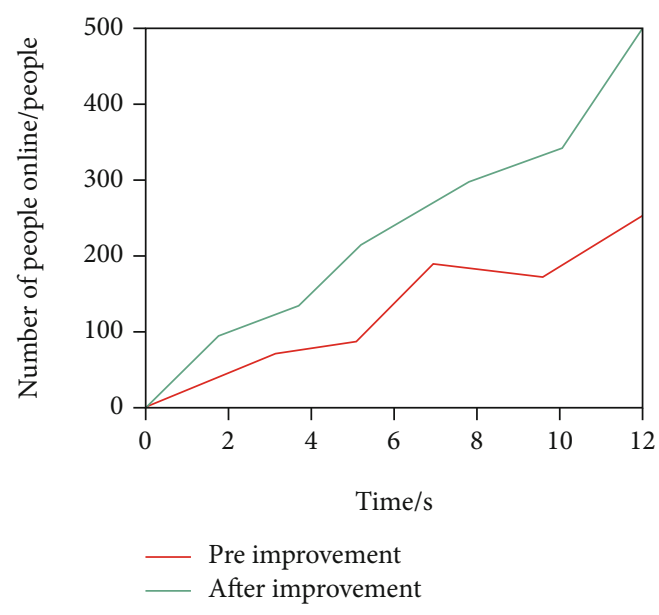

(a) The number of people online is less than 500

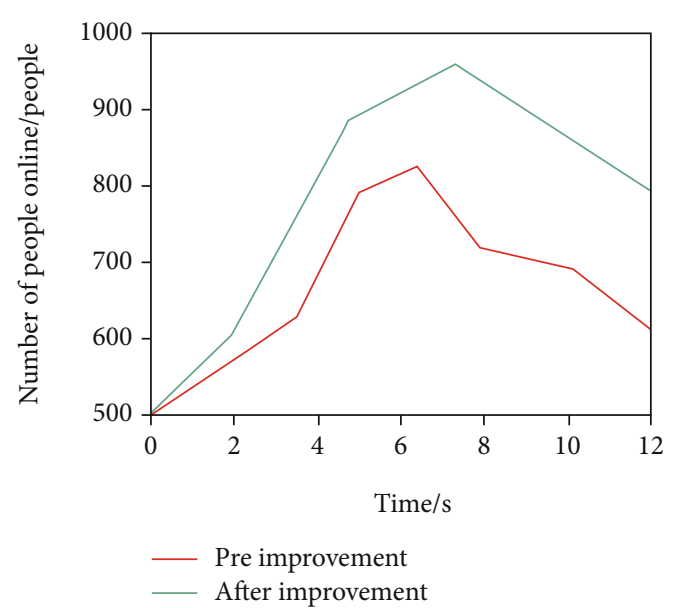

(b) The on-line number is greater than 500

Figure 7: Comparison results.

virtual teaching platform for garden design majors believes that the structure of the English virtual teaching platform for garden design majors is the basis of the overall existence of the platform, and the structural changes of the virtual teaching platform lead to changes in the overall performance of the platform. The structure of the English virtual teaching platform for landscape design majors determines the platform function. From the scientific point of view, the structure of the English virtual teaching platform for garden design majors has changed compared with the traditional English teaching platform for garden design majors. The virtual reality technology plays an important role in the English virtual teaching platform for garden design majors. Secondly, from the perspective of the relationship between the structural elements of the platform, the interaction and internal relationship between the elements of the English virtual teaching platform for garden design majors is more closely and more complicated.

The improved English virtual teaching platform for garden design majors designed in this paper has various characteristics. First of all, the platform can bring immersiveness to the user, also known as the sense of presence, which refers specifically to the true Extent of the learner as the protagonist in the simulated environment. Immersion is the degree to which learners perceive the virtual world. This sense of reality makes it difficult for learners to perceive and distinguish themselves in the virtual environment generated by a computer. Immersion is the foundation that makes the scene realistic. Constructivist learning theory advocates for learners to provide a real learning environment, so that learners actively form meaning constructions. The advantage of the virtual teaching platform is that it immerses learners in a realistic three-dimensional learning environment. It provides a reliable guarantee for learners to actively form meaning constructions. Secondly, it can give learners a better interactive experience. The interactive experience refers to the learner's operability of objects in the virtual world. Interactivity requires not only human-computer interaction, but more importantly, digital technology enables people to easily com- municate with each other through the Internet. Interaction can be understood as a two-way communication, which is reflected in the teaching process between students and teachers, students and learning resources, and students and students. In the virtual teaching platform, students are able to connect new knowledge with old knowledge through effective communication between students and teachers, so as to achieve the purpose of building the new cognitive structure. The platform can significantly enhance the students' conception. Conceptuality means that learners can acquire knowledge in all directions in the multidimensional information space of the virtual world, relying on their own perception and cognitive abilities. They seek to solve the problem perfectly by exerting subjective initiative. The fundamental purpose of the research and development of the virtual teaching platform is to expand human cognition and perception and to establish a harmonious human-machine environment. In the harmonious human-machine environment provided by the virtual teaching platform, the learner's subject status is fully reflected. The conception emphasizes that virtual reality technology should have a broad and imaginable space to broaden the scope of human cognition. It not only reproduces the real environment but also arbitrarily conceives an environment that does not exist or even impossible. Finally, the platform is multiperceived.

The so-called multiperception means that in addition to the visual perception of general computer technology, there are also hearing, force, touch, movement, and even taste, smell, and so on. From the perspective of the development of virtual reality technology, the ideal virtual reality technology should have all cognitive functions that human beings have. Due to the limitations of related technologies, especially sensing technologies, the perceptual function of virtual reality technology is limited to visual, auditory, force, tactile, and sports. After the above analysis, the improved English virtual teaching platform for landscape design majors designed in this paper has a good teaching effect and is suitable for application to the actual English teaching for landscape design majors. 
TABLE 2: Score results.

\begin{tabular}{|c|c|c|c|c|c|c|}
\hline Method & Student & $\begin{array}{l}\text { Teaching } \\
\text { clarity }\end{array}$ & $\begin{array}{l}\text { Teaching } \\
\text { fluency }\end{array}$ & $\begin{array}{c}\text { Human-computer } \\
\text { interaction } \\
\text { performance }\end{array}$ & $\begin{array}{c}\text { Resource } \\
\text { maintenance effect }\end{array}$ & $\begin{array}{c}\text { User } \\
\text { management } \\
\text { effect }\end{array}$ \\
\hline \multirow{10}{*}{ The method of this paper } & Student 1 & 9.92 & 9.98 & 9.97 & 9.97 & 9.97 \\
\hline & Student 2 & 9.98 & 9.97 & 9.98 & 9.99 & 9.98 \\
\hline & Student 3 & 9.94 & 9.97 & 9.99 & 9.99 & 9.99 \\
\hline & Student 4 & 9.89 & 9.97 & 9.98 & 9.98 & 9.99 \\
\hline & Student 5 & 9.87 & 9.99 & 9.98 & 9.96 & 9.96 \\
\hline & Student 6 & 9.86 & 9.99 & 9.98 & 9.96 & 9.98 \\
\hline & Student 7 & 9.99 & 9.98 & 9.94 & 9.94 & 9.96 \\
\hline & Student 8 & 9.99 & 9.96 & 9.93 & 9.95 & 9.99 \\
\hline & Student 9 & 9.91 & 9.95 & 9.95 & 9.95 & 9.97 \\
\hline & Student 10 & 9.93 & 9.96 & 9.96 & 9.99 & 9.97 \\
\hline \multirow{10}{*}{$\begin{array}{l}\text { Virtual teaching platform design } \\
\text { method based on cloud architecture }\end{array}$} & Student 1 & 8.23 & 8.41 & 8.61 & 8.19 & 8.23 \\
\hline & Student 2 & 8.26 & 8.46 & 8.62 & 8.21 & 8.25 \\
\hline & Student 3 & 8.29 & 8.49 & 8.68 & 8.24 & 8.28 \\
\hline & Student 4 & 8.64 & 8.25 & 8.67 & 8.28 & 8.29 \\
\hline & Student 5 & 8.35 & 8.37 & 8.54 & 8.29 & 8.31 \\
\hline & Student 6 & 8.16 & 8.46 & 8.52 & 8.31 & 8.35 \\
\hline & Student 7 & 8.24 & 8.59 & 8.53 & 8.36 & 8.38 \\
\hline & Student 8 & 8.26 & 8.27 & 8.59 & 8.38 & 8.42 \\
\hline & Student 9 & 8.34 & 8.26 & 8.47 & 8.45 & 8.46 \\
\hline & Student 10 & 8.46 & 8.23 & 8.46 & 8.47 & 8.45 \\
\hline \multirow{10}{*}{$\begin{array}{l}\text { Design method of virtual teaching } \\
\text { platform based on MVC }\end{array}$} & Student 1 & 7.51 & 7.56 & 7.49 & 7.61 & 7.42 \\
\hline & Student 2 & 7.58 & 7.59 & 7.67 & 7.63 & 7.46 \\
\hline & Student 3 & 7.52 & 7.58 & 7.82 & 7.59 & 7.49 \\
\hline & Student 4 & 7.53 & 7.51 & 7.81 & 7.57 & 7.51 \\
\hline & Student 5 & 7.46 & 7.54 & 7.69 & 7.52 & 7.53 \\
\hline & Student 6 & 7.59 & 7.53 & 7.64 & 7.49 & 7.59 \\
\hline & Student 7 & 7.61 & 7.61 & 7.62 & 7.48 & 7.61 \\
\hline & Student 8 & 7.68 & 7.48 & 7.61 & 7.46 & 7.64 \\
\hline & Student 9 & 7.83 & 7.49 & 7.69 & 7.59 & 7.68 \\
\hline & Student 10 & 7.45 & 7.68 & 7.71 & 7.52 & 7.69 \\
\hline
\end{tabular}

\section{Conclusion}

This paper mainly studies the English virtual teaching platform for landscape design majors in high security. The development technology of this platform mainly uses XAML,. NET, and Javascript. SQL Server 2005 is used as a background database, and the platform is designed by the more popular B/S three-tier architecture. Video teaching courseware, teacher-student interaction, English teaching for landscape design majors, and English teaching resources for landscape design majors are provided online by the platform, the goal is to provide students with a good online learning platform. The online English teaching module for landscape design majors implements an online compilation and running program.

In the case that the compiler is not installed, the compiler function of the browser is simply run through the compiled interface of the server, and the result of the compile and run is returned to the browser, so that the content of the virtual teaching platform is more diverse. The use of virtual reality technology enables the construction of virtual classrooms and virtual labs. Compared with the traditional online teaching platform, it has greatly improved in terms of security on Internet virtual teaching.

\section{Data Availability}

The raw/processed data required to reproduce these findings cannot be shared at this time as the data also forms part of an ongoing study.

\section{Conflicts of Interest}

The authors declare that there are no conflicts of interest regarding the publication of this study. 


\section{Acknowledgments}

This work was supported by the Project of Art Science in Shandong Province (201806506).

\section{References}

[1] W. Guo, N. Xiong, H. Chao, S. Hussain, and G. Chen, "Design and analysis of self-adapted task scheduling strategies in wireless sensor networks," Sensors, vol. 11, no. 7, pp. 6533-6554, 2011.

[2] N. Xiong, A. Vandenberg, and W. Han, "Green cloud computing schemes based on networks: a survey," IET Communications, vol. 6, no. 18, pp. 3294-3300, 2012.

[3] R. Othman and A. K. Zubaidah, "Assessment of plant materials carbon sequestration rate for horizontal and vertical landscape design," International Journal of Environmental Science \& Development, vol. 7, no. 6, pp. 410-414, 2016.

[4] R. T. Corlett, "The role of rewilding in landscape design for conservation," Current Landscape Ecology Reports, vol. 1, no. 3, pp. 127-133, 2016.

[5] G. K. Wong and C. Y. Jim, "Abundance of urban male mosquitoes by green infrastructure types: implications for landscape design and vector management," Landscape Ecology, vol. 8, no. 10, pp. 1-15, 2018.

[6] J. O. Kim and J. H. Suh, "A review of climate change adaptation policies applied to landscape planning and design in Korea," Landscape \& Ecological Engineering, vol. 3, no. 12, pp. 171-177, 2016.

[7] H. Liang, J. Zou, and K. Muhammand Junaid, “An improved genetic algorithm optimization fuzzy controller applied to the wellhead back pressure control system," Mechanical Systems and Signal Processing, vol. 142, article 106708, 2020.

[8] D. H. Li, B. S. Jiang, H. Y. Li, and X. P. Liu, "Design of experiment course "Computer-aided landscape design" based on flipped classroom," Computer Applications in Engineering Education, vol. 27, no. 9, pp. 234-240, 2016.

[9] S. Champeaux, P. Gouard, and R. Cousin, "Improved design of a multistage axial vircator with reflectors for enhanced performances," IEEE Transactions on Plasma Science, vol. 21, no. 9, pp. 31-38, 2016.

[10] I. Freeman, J. Salmon, and J. Coburn, “A bi-directional Interface for improved interaction with engineering models in virtual reality design reviews," International Journal on Interactive Design and Manufacturing, vol. 27, no. 13, pp. 112,2017

[11] Z. Huang, X. Xu, J. Ni, H. Zhu, and C. Wang, "Multimodal representation learning for recommendation in internet of things," IEEE Internet of Things Journal, vol. 6, no. 6, pp. 10675-10685, 2019.

[12] F. Stumpf, K. Schmidt, and T. Behrens, "Incorporating limited field operability and legacy soil samples in a hypercube sampling design for digital soil mapping," Journal of Plant Nutrition and Soil Science, vol. 5, no. 3, pp. 499-509, 2016.

[13] H. R. Sun and H. Wang, "Optimization design simulation of ecological balance of urban green landscape," Computer Simulation, vol. 7, no. 2, pp. 214-217, 2018.

[14] H. Liang, D. Zou, Z. Li, K. Muhammand Junaid, and Y. Lu, "Dynamic evaluation of drilling leakage risk based on fuzzy theory and PSO-SVR algorithm," Future Gerneration Computer Systems, vol. 95, no. 7, pp. 454-466, 2019.
[15] H. Zheng, W. Guo, and N. Xiong, "A kernel-based compressive sensing approach for mobile data gathering in wireless sensor network systems," IEEE Transaction on Systems, vol. 48, no. 12, pp. 2315-2327, 2017.

[16] Y. C. Liu, Y. Huang, and X. Li, "Research on midpoint potential balance of NPC three-level inverter based on fuzzy virtual space vector modulation," Journal of Power Supply, vol. 10, no. 9, pp. 61-66, 2018.

[17] X. L. Meng, L. D. Wu, and S. B. Yu, "Research on resource management mechanism of spatial information network based on virtualization," Journal of China Academy of Electronics and Information Technology, vol. 6, no. 8, pp. 47-52, 2018.

[18] Y. Zhou, D. Zhang, and N. Xiong, "Post-cloud computing paradigms: a survey and comparison," Tsinghua Science and Technology, vol. 22, no. 6, pp. 714-732, 2017.

[19] Z. Liu, B. Hu, B. Huang, L. Lang, H. Guo, and Y. Zhao, "Decision optimization of low-carbon dual-channel supply chain of auto parts based on smart city architecture," Complexity, vol. 2020, Article ID 2145951, 14 pages, 2020.

[20] Y. Zhang, R. Zhu, Z. Chen, J. Gao, and D. Xia, "Evaluating and selecting features via information theoretic lower bounds of feature, inner correlations for high-dimensional data," European Journal of Operational Research, vol. 290, 2020.

[21] H. Liang, A. Xian, M. Mao, P. Ni, and H. Wu, "A research on remote fracturing monitoring and decision-making method supporting smart city," Sustainable Cities and Society, vol. 62, article 102414, 2020. 